\title{
ON A RESULT OF LEINDLER
}

\author{
R. N. MOHAPATRA AND F. L. SALZMAN
}

Abstract. In this paper we give an alternative proof of a result of Leindler on Hardy type inequalities. This method can also be used to obtain alternative and simpler proofs of other results.

\section{Mathematics subject classification (2000): 26D15, 42A20.}

Key words and phrases: Hardy's type inequalities, sequences, series.

\section{REFERENCES}

[1] Davies, G. S. And Petersen, G. M., On an inequality of Hardy's (II), Quart. J. Math. (Oxford), 15 (1964), 35-40.

[2] Hardy, G. H. AND LitTlewood, J. E., Elementary theorems concerning power series with positive coefficients and moment constant of positive functions, J. Reine Angew. Math., 157 (1927), 141-158.

[3] JohnSON, JR., P. D. AND MOHAPATRA, R. N., Inequalities involving lower-triangular matrices, Proc. London Math. Soc., 41 (1980), 83-137.

[4] LeINDLER, L., Generalization of inequalities of Hardy and Littlewood, Acta Sci. Math. (Szeged), 31 (1970), 279-285.

[5] LEINDLER, L., Further sharpening of inequalities of Hardy and Littlewood, Acta Sci. Math. (Szeged), 54 (1990), 285-289.

[6] LeINDLER, L., Some inequalities of Hardy-Littlewood type, Analysis Mathematica, 20 (1994), 95-106.

[7] NÉMETH, JózSEF, Generalization of the Hardy-Littlewood inequality, Acta Sci. Math. (Szeged), 32 (1971), 295-299. 